\title{
Self-financing for Conservation Based on Global Experiences - Case Study Preserving the Architectural Heritage of Historical Tripoli, Lebanon
}

\author{
Khaled El-Daghar ${ }^{1}$ \\ ${ }^{I}$ Assistant Professor - Beirut Arab University, Faculty of Architecture - Design and Built Environment - Tripoli \\ Branch, Lebanon. \\ E-mail: k.eldaghar@bau.edu.lb
}

\begin{abstract}
Funding has always been important for the continuity of any conservation project and the achievement of the desired results. Its impact is particularly evident in the projects regarding the heritage domains; it clearly shows the importance of having multiple participating bodies/entities and diverse self-funding sources without relying solely on governmental agencies or governmental funding, particularly in the developing countries where there is a clear deficiency in the countries' potential ability to meet the developmental needs of these heritage areas. The study aims to illustrate the relationship between continuity of financing operations and the sustainability of conservation projects. Financing and its efficiency equally affect all the phases of the project: the pre-implementation stage, the implementation stage, and the post-implementation/operation stage (maintenance and follow-up). This is due to the fact that financing operations do not only affect the possibility of implementing a project, but also affect the quality level of the preservation, whereby buildings lose their values both tangible and intangible. This is due to the inaccuracy of studies, lack of precise equipment for work or lack of analyzing the different possibilities that might lead to the destruction or damage of buildings. In this context, light will be shed on different cases and models of global conservation projects in several countries by investigating and analysing its financial aspects to establish the different circumstances surrounding each project, such as goals and stages, and identifying the positive and negative points of each project. This will be done through several axes, legal, managerial, financial, and popular participation, the most important of which is the self-financing aspect. Each case will be discussed and evaluated separately at the level of the building, urbanization and society as an integrated system to demonstrate their characteristics, namely successful architecture, historical gatherings, and surrounding community life. The paper proposes some methods for dealing with historic buildings as part of the urban and architectural heritage, where the legal, managerial, financial and community participation, especially the self-financing level, are considered in order to conserve these buildings.
\end{abstract}

(C) 2019 The Authors. Published by IEREK press. This is an open access article under the CC BY license (https://creativecommons.org/licenses/by/4.0/).

\section{Keywords}

Self-financing; Conservation; Continuity; Urban and Architectural Heritage; Tripoli Lebanon

\section{Introduction}

Heritage buildings are a national treasure despite the negative vision of some conservatives in terms of the economic assessment of such buildings. Moreover, historical and heritage buildings cannot be separated from the economic movement for the sake of their continuity. Thus, the need for funding sources for their conservation in historical areas in developing countries is increasing steadily due to several reasons. These include the increase in the impact 
seriousness of various damage factors on heritage buildings, especially natural factors, the huge numbers of value buildings and the high costs of conservation and maintenance of historical and heritage buildings (Harrison, 2006).

The sources of financing for conservation vary between public, private, and nonprofit funders; however, such finances can be taken from loans, grants, tax incentives, market mechanisms and self-financing. Conservationists have traditionally relied upon private, philanthropic capital in the form of solicited donations and foundation grants, also public, governmental funds in the form of tax incentives, ballot measures, bonding, agency appropriations, etc., to fund conservation projects. Although governments and philanthropists provide a moderate amount of funds, conservationists believe that there is a shortage in the capital required to conserve the architectural heritage and value buildings, so it may be necessary to resort to self-financing for conservation projects (Pålsson Skarin, 2011; Pickard, 2009).

The study aims at reviewing financing policies and self-financing in particular, funding entities/bodies and their role in determining the level of conservation, for example, governmental entities, community, private investments and non-governmental entities and organizations. Financial policies considerably affect the decision-making process concerning the conservation as it is possible that the effect is negatively against the interests of the historical and heritage buildings due to the lack of adequate financial resources for maintenance and saving, the selection of a few important historical and valuable buildings to be saved, or the neglegence of a large number of them wherenthey are not registered globally. This is in addition to conceding some of the heritage buildings to the countries that carried out the conservation process (Ginzarly \& Teller, 2016).

Conservation projects can be funded by the individuals of the society who sympathize and are interested in the heritage buildings. The concerned international organizations for science, arts and culture led by UNESCO (United Nations Educational, Scientific and Cultural Organization) is also considered as a major source of funding for conservation projects. Furthermore, the role of private investments in financing projects for the conservation of heritage buildings within the context of their re-use for with profitable revenue can also be a major source of funding (Khan \& Zhang \& Hashmi \& Bashir, 2010). This can contribute to the process of managing the conservation of architectural heritage and its forms in the city of Tripoli by following global experiences in conservation.

\section{Self-financing for conservation projects of heritage buildings}

Self-financing can be defined as a firm or project that generates its growth capital from its own income, instead of acquiring it from external sources such as investors or lenders (Business Dictionary, 2019). Therefore, in our case, it means utilizing the building(s) as a profit earning project that would finance the conservation. Among the indicators of the success of conservation projects is that the project will cover its expenses without the need for external interference to ensure the continuity of projects. For example, the development of the Al-Darb Al-Ahmar (Red Road) district and the restoration of the northern Stone Wall of Cairo, where Al-Azhar Park and the financial income it brings as a financial resource have been allocated as one of the main sources for the continuity of the Al-Darb AlAhmar project, as the return of this park pays for the completion of the remaining maintenance and follow-up works of the heritage buildings in the area (Aga Khan Historic Cities Programme (AKHCP), 2007; UNESCO World Heritage Center (WHC), 2012).

\subsection{Cost of the project}

The cost of the project is divided into several main types (as shown as Figure 1): initial cost, financing cost, alteration cost, replacement cost, etc. (Harrison, 2006); (UNESCO World Heritage Center (WHC), 2012): 


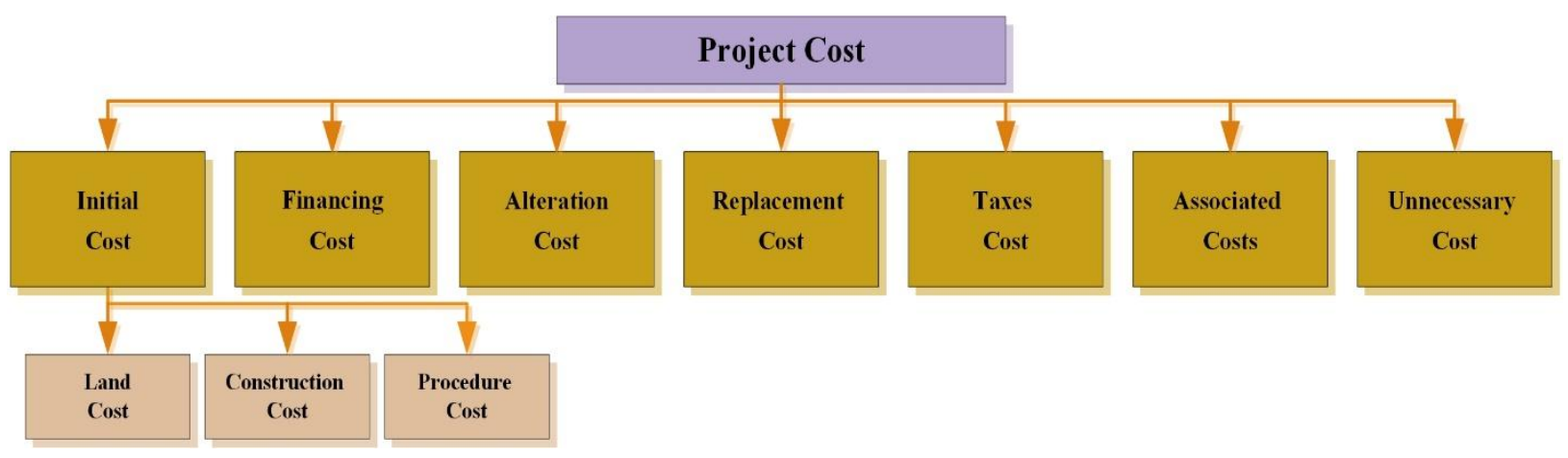

Figure 1: The cost types of the project (Updated by the Author)

Initial cost: it includes several branch elements such as, the cost of the land (purchase cost of land, licensing procedures and initial legal steps), the cost of construction (labor cost, materials, site coordination and supervision of implementation). It represents a dynamic value change and the cost of procedures (it is a value associated with the final product) which represent the fees, taxes and licenses (Harrison, 2006).

Financing cost: it includes the costs of any section associated with the entity's capital costs (Harrison, 2006).

Alteration cost: the cost required to make an adjustment to the basic function of the building. For example: the conversion of a residential building into a museum (UNESCO World Heritage Center (WHC), 2012).

Replacement cost: this cost ensures that the building is restored to its basic function (i.e., changing it while maintaining the function) (Aga Khan Historic Cities Programme (AKHCP), 2007).

Taxes cost: these are the taxes and administration fees imposed by governmental entities on the buildings. This cost is reviewed with any change in the tax and return laws imposed on buildings (Harrison, 2006; UNESCO World Heritage Center (WHC), 2012).

Associated costs: these are to ensure the continuity of the project, where it is preferable to issue a type of insurance on the project. For example: depositing an amount by the name of the project in a bank and the return proceeds in the follow-up and maintenance (Harrison, 2006).

Unnecessary cost: a cost that is dispensable in the project without causing any damage to the basic function. This cost is defined as the cost whose incurrence cannot increase the value of an element function such as, durability, appearance or returning any benefit. The non-essential cost can be determined by comparing a set of expenditure alternatives. The difference in expense between two alternatives is an unnecessary cost provided that the two alternatives perform the same function without affecting durability, quality or final image of product as well as the aesthetic aspects of the project (Aga Khan Historic Cities Programme (AKHCP), 2007; UNESCO World Heritage Center (WHC), 2012).

\subsection{Who is involved in conservation?}

It means the participating entities and sources of funding for the conservation. The importance of the multiplicity of the participating agencies and the sources of funding without relying on government agencies or government funding only, especially in developing countries because of the lack of the possibilities of these countries to meet the needs of conservation projects is helpful. Therefore, a successful conservation project depends on more than one aspect of funding and implementation (Clausse, 2013). Thus, it is clear in the conservation projects that the greater the number of funders is, the greater the success of the project. Many of these parties are among financiers of projects, including governmental entities, investors and international non-profit organizations, such as aid, as well as, the society through national communities, foreign missions, and aid and grants (Yousif, 2014).

As for the financing of historical buildings, it is often dependent on public funds (governmental financing) or international bodies, which are insufficient to provide financing for such a large number of buildings under the current economic conditions. Actually, current policies exploit only about $1 \%$ of the total historical buildings as monuments; therefore, they can barely cover the maintenance cost of these buildings. This leads to the damage and collapse of 
many of them despite their presence within the area of interest. Financing entities have a key role in determining the level of conservation operations (Clausse, 2013; Yousif, 2014) which is represented as follows (as shown as Figure 2):

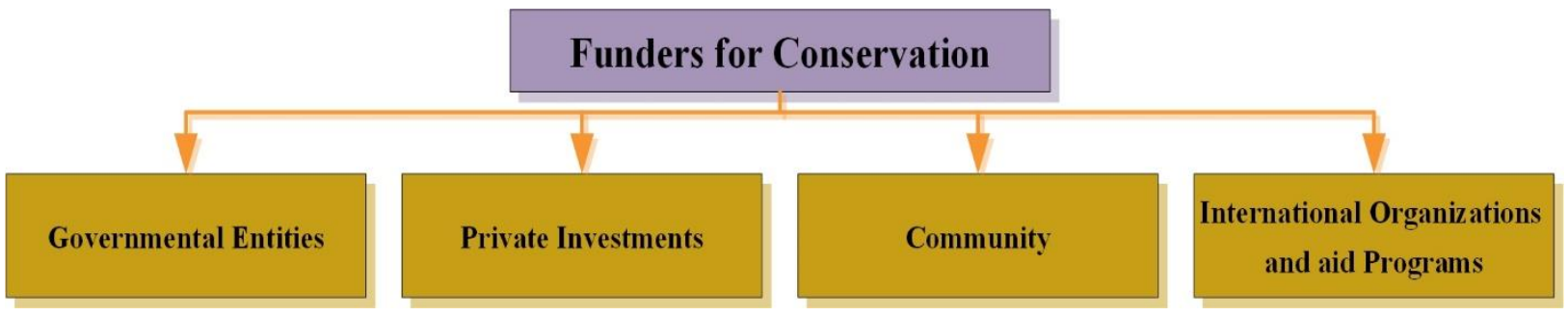

Figure 2: The sources of funding for conservation (Updated by the Author)

Government entities: these are the ministries and entities that are mainly concerned with the provision of infrastructure and services, and the creation of legislations and the administrative and regulatory entity, as well as national banks contributing to small enterprises. However, when relying on government funding only, this leads to the loss of a large amount of architectural heritage due to the inability of the state budget to maintain all buildings; therefore, the focus will be on buildings of the first rank only, especially the visible buildings located in the capital and buildings with touristic uses (Rashed \& Fikri \& Belqasi, 2013; Al-Manshawi, 2013).

Private investments: these are profit organizations that provide economic activity to the region through investment projects, which are appropriate to the nature of the heritage domain. In turn, this increases the income and production and ensures continuity of the project. It also contributes to the heritage buildings moving from the service space to the investment space. This increases their value and allows investment in functions that generate a large return covering the cost of maintenance and follow-up (Al-Manshawi, 2013).

Community: it participates in the projects through popular organizations and non-governmental organizations (NGOs), which contribute to raising awareness of the importance of conserving, enabling exchange of experiences in this field and providing financial and technical support. This contributes to raising the level of the conservation projects and investments would alleviate some of the burden on the State (Rashed \& Fikri \& Belqasi, 2013).

International organizations and aid programs: they conduct activities that do not generate profits and exist within the scope of their interests, such as the provision of services and facilities, the restoration of historical and value buildings, and other specialized and important works of society. The project of maintaining historic ranges or buildings requires the participation of multiple efforts and the exploitation or investment of previous experiences in similar projects carried out in other countries. This cannot be performed except through regional and international organizations concerned with this area (as shown as Figure 3 and 4). As well as, aid agencies, such as GTZ and other bodies that contribute a lot to the area of conservation and development in the developing countries (Rashed \& Fikri \& Belqasi, 2013; Al-Manshawi, 2013).

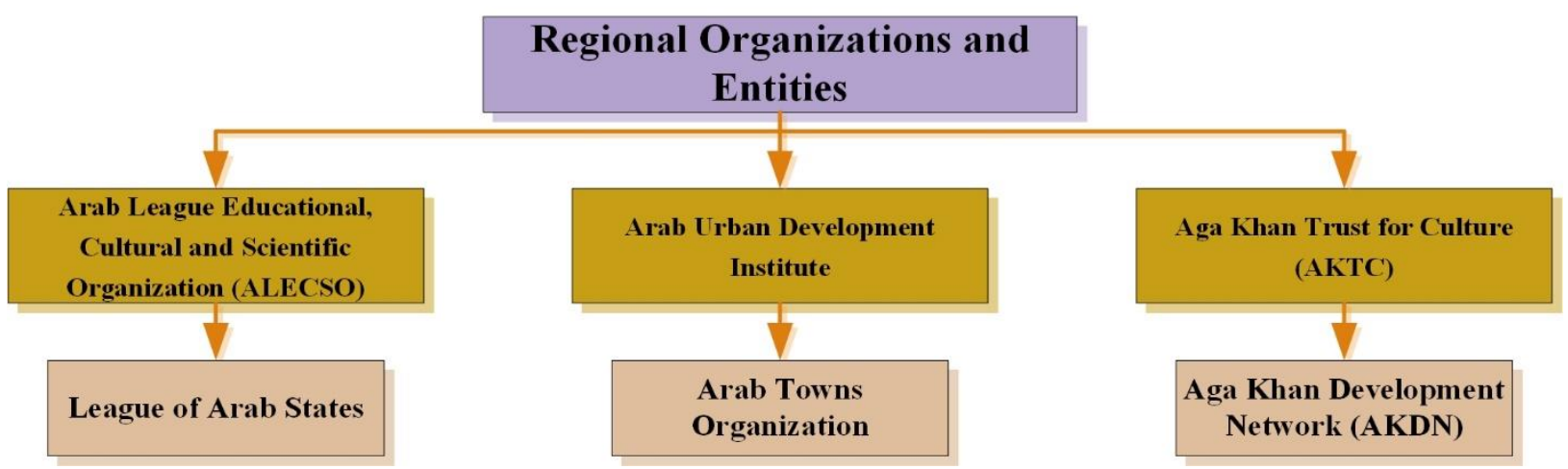

Figure 3: The regional organizations and entities concerned with conservation (Updated by the Author) 


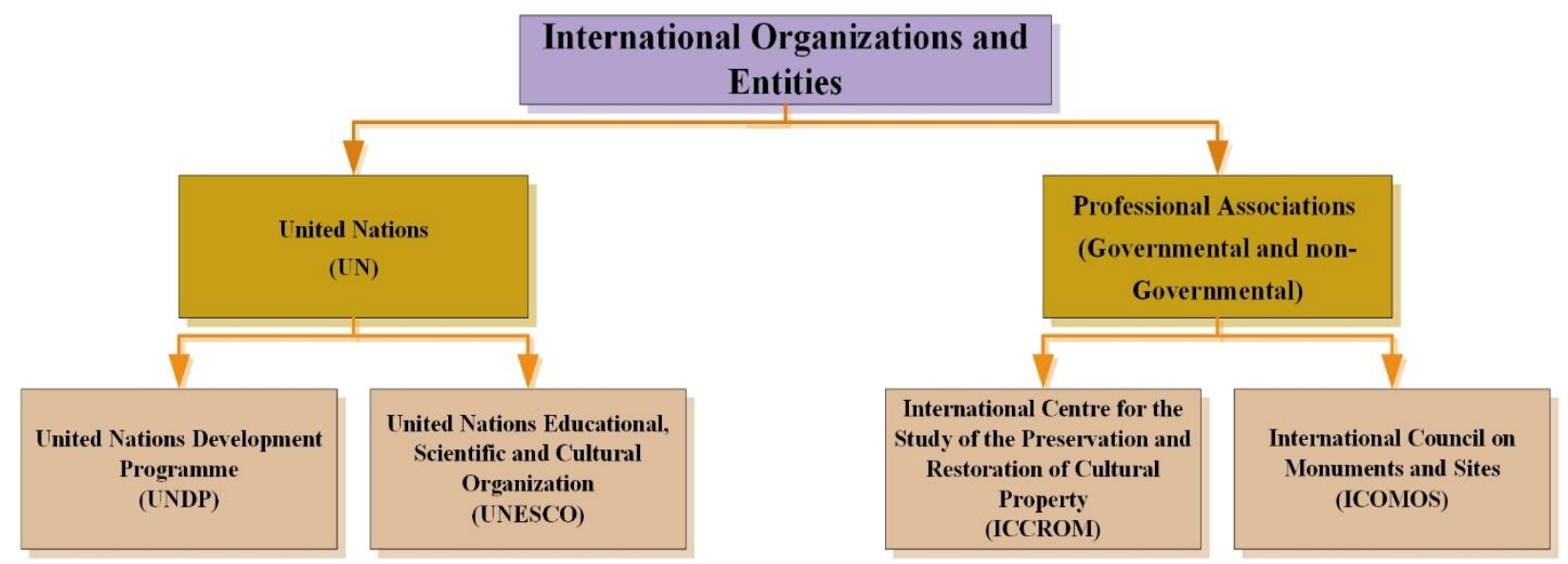

Figure 4: The international organizations and entities concerned with conservation (Updated by the Author)

\subsection{Finance policies' role in conservation projects}

Finance policies significantly affect decision-making in conservation. As a result, these policies may have a negative effect against the interests of the heritage buildings due to the insufficient financial resources for conservation and rescue. For example, in the project of saving Nubia heritage drowning in Egypt after the increase in the level of water of Nasser's Lake, due to the lack of funding resources, the government resorted to international aid and announced an international call to sell the monuments in exchange for saving a few of them. The result was the selection of a few important monuments to be saved and neglecting a large number of them and not to register them globally. This is in addition to waiving some monuments to the countries which performed the rescue operations (Abdel Fattah, 2012; El Esawy, 2012).

Therefore, the finance policies and processes do not only affect the possibility of a project implementation, but also affect the quality of conservation work standards. If work was below standard, this would lead to the buildings' loss of their artistic, material and heritage value, for several reasons; inaccuracy studies, lack of precise instruments for work and inefficiency of analyses, which leads to the destruction and damage of buildings. The absence of governmental supervision and the lack of support for conservation works, which expose many heritage buildings to neglect due to lack of funding sources to preserve them (Abdel Fattah, 2012) make self-financing for conservation projects an essential purpose.

\subsection{Phases of conservation and its relationship to the continuity of funding}

The conservation methodology illustrates the positive relationship between the continuity of financing and the continuation of conservation projects, which can be divided into three basic phases (Tabellini, 2010) (as shown as Figure 5):

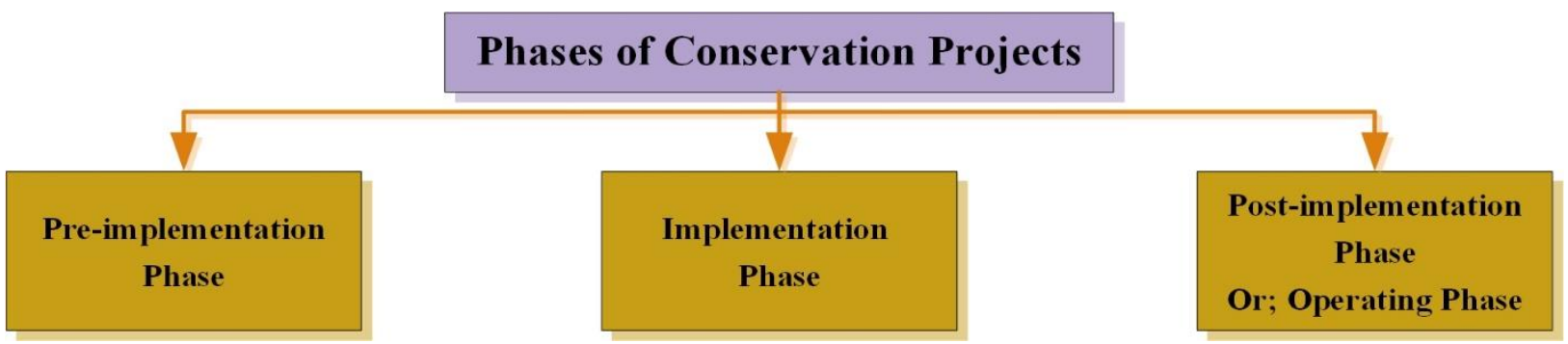

Figure 5: The basic phases of conservation projects (Updated by the Author)

Pre-implementation phase: it is the stage of collecting and analyzing information, finding the strategies through which to deal with the involved tasks, deciding on the optimal alternative, and setting the work plan. This is one of the least expensive phases in conservation projects, but it must be performed ideally to the fullest extent because failure to collect or analyze data leads to finding incorrect superficial alternatives that negatively impact the continuity of the project (Felix, 2007; Tabellini, 2010). 
Implementation phase: it is the most expensive stage because of its considerable requirements in knowing details of the tenders and the contracting that will take place in the project, in addition to the trained manpower and its high cost. This phase concludes with delivery and operation of the project (Felix, 2007).

Post-implementation or operating phase: it is one of the most important stages because the follow-up and maintenance of any damage or deterioration that emerges in the conserved building and its surroundings would in turn maintain the continuity of the project. Therefore, it is advisable to put some investment in the surrounding area to generate a continuous profit, and this profit is allocated to the maintenance and follow-up of those buildings. In some places, there has been a deterioration and decline after the completion of the conservation projects due to the lack of continuity in the project funding after its completion (Felix, 2007; Tabellini, 2010).

\section{Methodology}

The study will handle self-financing as one of the alternatives in the projects of the conservation of historical buildings. It will find investment projects to finance conservation projects along with the possibility of exploiting the project or one of its elements, existing components and its inherent potentials to obtain self-financing for the continuity of the conservation projects. The research depends on a systematic methodology via reviewing selffinancing for conservation projects of heritage buildings: cost of the project, parties of conservation, sources of funding for conservation and regional and international organizations and entities concerned with conservation. Moreover, it will demonstrate the finance policies' role in conservation projects, and phases of conservation and its relationship to the continuity of funding. In addition to this, the case study for preserving the architectural heritage of Tripoli based on global experiences, which will analyze the condition of urban heritage and value buildings. Then, illustrate the global experiences of self-financing for conservation projects in Britain, Kingdom of Saudi Arabia and Egypt, to achieve special guidelines and recommendations as bases and rules of dealing with heritage buildings in Tripoli at the legal and administrative, popular participation and financial aspects. Self-financing for conservation projects to ensure its continuity, and the re-employment of historical and value buildings in functions that serve the community of old Tripoli will also be discussed.

\section{Case study preserving the architectural heritage of Tripoli based on global experiences}

\subsection{Background of Tripoli, Lebanon}

Tripoli is Lebanon's second largest city after the capital Beirut and the second largest city worldwide in terms of its Mamluk Heritage after Cairo. However, due to the deterioration of the economic, urban, and political conditions of the city, as well as the history of wars in Lebanon, the condition of heritage buildings was severely affected and this caused them to be destroyed during the period of those wars. In addition to other factors, such as neglect for long periods, this negatively affected the city's heritage and monumental legacy (as shown as Figure 6). Another cause is the collapse and wrong restoration with materials that may damage the buildings and exclude them from the archaeological classification and other infringements on the historical buildings. All these factors prevented the presence of Tripoli on the map of world tourism. Therefore, this requires rapid and decisive intervention to deal with what remains of this urban heritage and value buildings, and preserve it for future generations (El Taweel, 2006; Ginzarly \& Teller, 2016). 


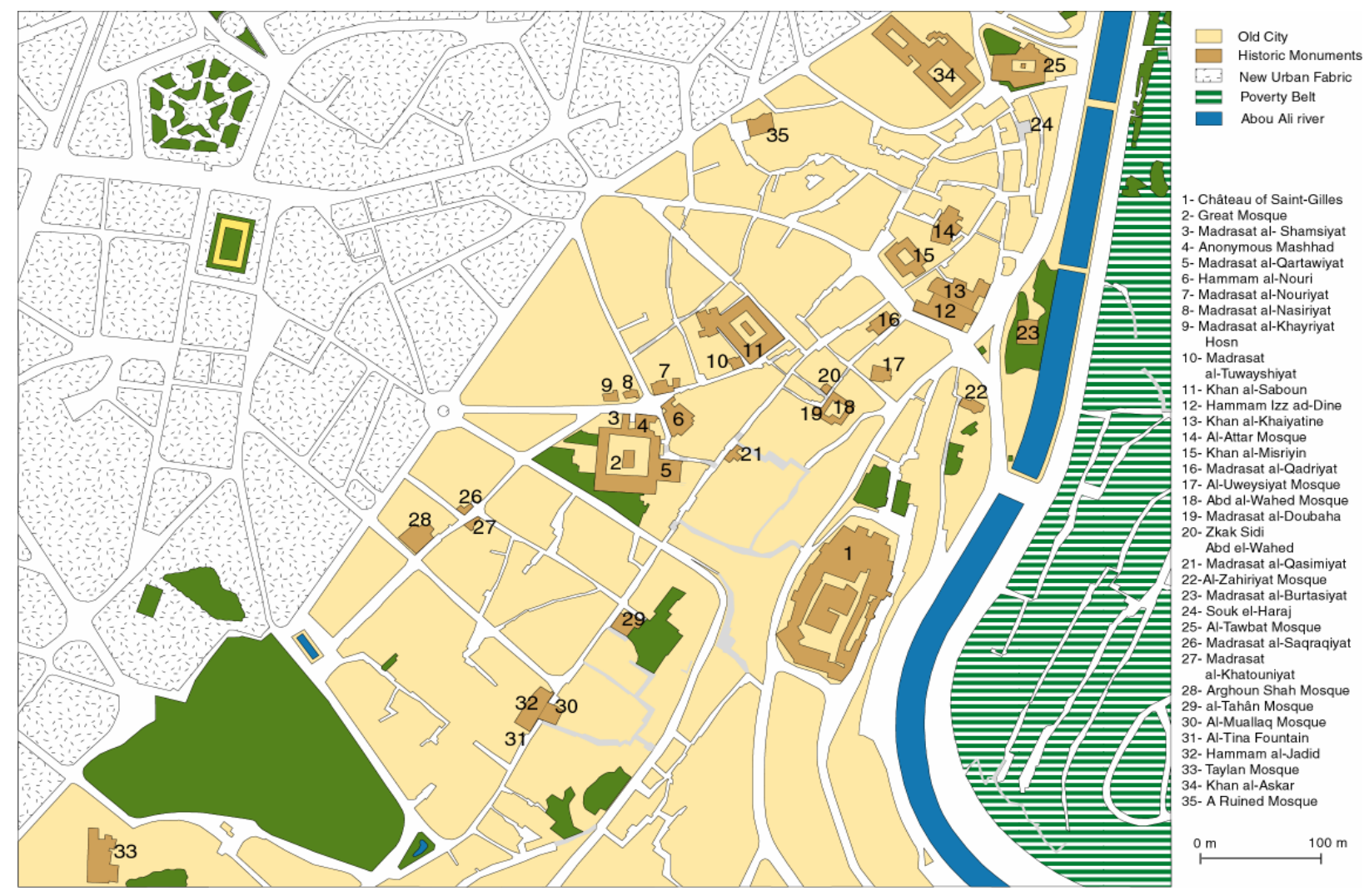

Figure 6: The map of heritage areas in the historical city of Tripoli (Updated by the Author)

\subsection{Global experiences of self-financing for conservation projects}

Factors that influence the ability of success, appropriation and continuity for conservation projects are various, most importantly are legal and administrative, popular (community/citizens) participation and financial aspects (BungeVivier \& Martínez-Ballesté, 2017; Felix, 2007; Hezel \& Francis, 2009). The following are some international and regional examples that have dealt with the conservation field:

\section{Self-financing for conserving heritage in Britain}

British and English expertise was concerned with preservation in the late 1960s. The first interest was given to the centers of historical cities dating back to the middle Ages, which included several characteristics of successful architectural and historical gatherings as well as the surrounding community life, "i.e., dealing at the level of building, urban and society as an integrated system". Britain is considered one of the first countries to establish the rules for dealing with heritage buildings as a part of the urban plans. Actually, it has developed a strict system to conserve these buildings. Thus, financial, legal and administrative aspects have affected organization of conservation processes (Pollard \& Cousins, 2008; Hezel \& Francis, 2009).

- Legal and administrative: in 1917, the English Urban Secretariat was established. It introduced the new concept of the conservation of historic areas. It also directed all local entities to renovate areas of historical interest and special architecture of the desired distinctive nature to conserve and develop them as the local planning authority sets plans and schemes and implements through them (Hanafi, 1993; Pollard \& Cousins, 2008).

- Popular/community participation: Britain is interested in the participation of all parties in the conservation project to ensure its continuity. Therefore, it is interested in publishing all matters dealing with the conservation project and taking the opinion of the public into account. In addition to the establishment of national associations and civil entities for the conservation projects composed of the users of heritage buildings, as well as replacement of heritage buildings in functions serving the community. This would result in the sympathy of the members of the community with the heritage buildings, and thus, conservation and maintenance of buildings becomes one of the objectives of its users (Felix, 2007; Hezel \& Francis, 2009). 
- Financial aspects: the government provides grants for all heritage buildings: $50 \%$ for the maintenance and restoration of separate buildings, $25 \%$ for local projects and special support for the bodies depending on the importance of the building (Hanafi, 1993; Felix, 2007).

Conservation policies have not been centralized "i.e., depending solely on the government", but they have been shared by property owners through real estate investments and building users by their commitment to short-and mediumterm maintenance programs. Replacement is considered one of the most important conservation policies, which have helped to create funding sources other than the governmental source, which are the owners of buildings and their users that helped to raise the level of conservation. Funding can be classified into four main sources and replacement (Pollard \& Cousins, 2008).

1. The government: through direct funding from its resources for governmental conservation work, or providing loans and assistance to individuals to carry out private conservation projects. Government conservation projects rely on the budget allocated to them, taking into consideration the possibility of recovering these funds through the citizens who use the project (Hezel \& Francis, 2009).

2. Public and private organizations and entities: UNESCO (International Organization for Science, Arts and Culture) is deemed as the main funding source for conservation projects. Private conservation organizations, most of which, rely on the revolving fund principle, "i.e., invest the basic capital in the purchase of old buildings for restoration and maintenance, and then sale or rent", and use the profit of the resulting revenues financing another project and this process is repeated (Felix, 2007; Pollard \& Cousins, 2008).

3. Private investments: this plays a key role in the financing of projects for the preservation of heritage buildings within the project of their replacement in uses of profitable returns. This encourages businessmen to invest their money in such projects and other incentives encourage them too such as; exempting an amount equal to the value of their contribution from taxes and other forms of encouragement and motivating of involving investors in funding conservation projects (Pollard \& Cousins, 2008).

4. Owners and users (self-financing): the most important source of funding from users is considered to be the proceeds of the entry tickets of heritage buildings and museums, which are usually allocated to the work of conservation and maintenance of these buildings or other value buildings. This revenue can be developed by commercial uses adjacent to heritage buildings (Pollard \& Cousins, 2008).

Decentralized policy for decision making and implementation in conservation projects is considered one of the most successful policies, as multiplicity of funding entities helps to ensure interest from different levels (Pollard \& Cousins, 2008; Hezel \& Francis, 2009), also self-financing will cover its expenses without the need for external interference to guarantee continuity of the project.

\section{Self-financing for conserving heritage in the Kingdom of Saudi Arabia}

In view of the special importance that Jeddah occupies in relation to the Kingdom of Saudi Arabia and in the light of developing old Jeddah to conserve the existing schematic and architectural heritage from loss, especially with what the old city has turned to through time and individual encroachments. For this reason, the Municipality of Jeddah has prepared a complete project for the development of the old city of Jeddah, which includes: renovation of value buildings and distinctive character, as well as the restoration of public environment within the old city (El Esawy, 2012; Sultan, 2013).

- Legal and administrative: the origin of the city of Jeddah descends from the tribe of Otter (Qodaah), which settled in this region 2500 years ago and was named after one of its descendants. The Center for Planning and Architectural Studies has proposed for the integration of development work in the city the need to revive traditional activities once again within the old city. Thus, the conservation, protection and development approaches are integrated to encompass both the architectural and socio-economic activities. In general, all the projects presented have architectural significance derived from the old city itself. The architectural elements of the existing historical buildings, whether these elements were at the level of the horizontal projection and its architectural design, at the level of directions or at the level of the idea of the governing 
relations, which reflected the function and its activation with the prevailing customs and values (Etzioni, 2007; El Borombaly, 2015).

- Popular/community participation: the old city was divided into three areas to facilitate implementation, follow-up, and evaluation. Each zone has its own appropriate policy of conservation and development. Therefore, the first area contains most of the historical heritage buildings and the uses and structural requirements are specified to conserve its old character, while the second zone contains the services of the commercial and administrative area within an urban pattern compatible with the old city. As for the third area, conditions and requirements for construction and future development of the existing residential uses were identified. The project has been implemented performed in two basic phases (Etzioni, 2007; Sultan, 2013).

The first phase: is specialized in the urban fabric; it was concerned with the introduction of basic services, while paving roads and areas, and lighting and fountains works.

The second phase: it was devoted to the restoration of the old buildings, after the development of a large database for each house. Owners of old buildings were encouraged to restore their houses and provide assistance to them. Therefore, the population played a prominent role in achieving the objectives of this phase. Among the objectives of this stage is to conserve the original fabric of the region without scratching it, whether by highways or streets of cars.

- Financial aspects: the upgrading of the urban heritage environment in Jeddah is one of the mono-funded projects as the principal responsible entity for the financing process is the Municipality of Jeddah. It has played a major role in the conservation of the city. For example: it provides adequate funding and provides the necessary material and technical support to encourage the population to renovate their homes, while contributing to the provision of necessary expertise and techniques for the conservation processes. In addition to, enhancing the urban aspects in integration with the social urban life in the city and providing the requirements of life to reduce the migration of its population (Sultan, 2013). Otherwise, it is clear that there is no self-financing in Jeddah. It mainly depends on mono-funding from the municipality that may hinder conservation projects if the municipality cannot continue the funding process.

The city of Jeddah is a good model for dealing with heritage buildings especially that this city is one of the cities where the nature of the population has changed completely. In addition, the evaluation standards of the fabric as a whole for the inhabitants of the place have changed. Hence, the main challenge in the conservation of this distinctive fabric is the revival and appreciation of this old area in the eyes of its users, and finding uses that ensure the survival of dealing with these buildings to ensure their continuity (El Esawy, 2012).

The mono-financing provided by the Jeddah municipality is considered as one of the project's critical points. The multiplicity of funding agencies helps in the multiplicity of opinions and finding many alternatives to deal with the place, although mono-funding determines responsibility and ensures follow-up of the project (Etzioni, 2007; El Borombaly, 2015). However, some obstacles may appear if municipality funding gets low or disappeared for any coercive or political reason, on the contrary in case of self-financing.

\section{Self-financing for conserving heritage in Egypt}

Egypt has a long history and a multiplicity of civilizations (Pharaonic, Roman, Coptic, Islamic, etc.), so it has gained a great deal of international excellence because of the great numbers of monuments it has. It has about one third of the world's monuments, in addition to various heritage and value buildings (El Esawy, 2012; UNESCO World Heritage Center (WHC), 2012).

In spite of this cultural discrimination, there are many problems facing the heritage and historical areas in Egypt. The financial, political, administrative and technical capacity does not guarantee the maintenance, conservation and follow-up of all historical and value buildings. Therefore, Egypt resorted to grants, loans and foreign entities to contribute and participate in the conservation projects. Nevertheless, much of the Egyptian heritage was not been 
restored or taken as much attention as it deserves (Aga Khan Historic Cities Programme (AKHCP), 2007; Ministry of Culture, 2010).

- Legal and administrative: there are a number of committees and bodies dealing with the scope of urban architecture, including (Ministry of Culture, 2010; Al-Manshawi, 2013):

The Supreme Council of Antiquities (SCA): was a department within the Egyptian Ministry of Culture from 1994 until January 2011, when it became an independent ministry, the Ministry of State for Antiquities (MSA). It was the government body/entity responsible for the conservation, protection and regulation of all antiquities, museums, monuments, heritage and historical areas and archaeological excavations in Egypt.

The entities/bodies responsible of antiquities affairs: the President of the Republic, the Prime Minister, the Minister of Culture, etc.

The entities/bodies responsible for management of historical areas: the Ministry of Endowments, the Ministry of Culture, the governorates, the Urban Planning Commission and the Committee for Conservation of Fatimid Cairo in the Ministry of Housing and Utilities.

The Foreign and international entities/bodies working on conservation projects: for example; German Technical Cooperation Agency (GTZ), U.S. Agency for International Development (USAID), and the American Research Center in Egypt (ARCE).

- Popular/community participation: media policies are the primary incentive for popular participation. There is no clear role for the various mass media in spreading awareness of the importance of conserving the urban heritage, which reduces public interest in cooperation in the work of conservation projects (Al-Manshawi, 2013).

Seminars and conferences on conservation are directed mainly to specialists and do not care to direct these seminars to the public to raise their awareness. On the other hand, the role of Non-Governmental Organization (NGOs) and foreign aid programs that stimulate participation and encourage the active participation of the population and users of historical areas cannot be denied (Rashed \& Fikri \& Belqasi, 2013).

- Financial aspects: although there are many donating bodies to conservation projects in Egypt from governmental agencies, foreign and international aid and grants and Arab contributions, the conservation process is not subject to a state-organized plan, which makes it no more than scattered efforts and reduces its efficiency on the whole scale (Rashed \& Fikri \& Belqasi, 2013).

Government funding is the basis in the conservation processes. There is no system that encourages individuals to contribute or participate financially except in the narrowest extent through national associations. Therefore, most buildings are left without conservation or maintenance, leading to their deterioration and decline. For example: Cairo has lost about 122 monuments over the last fifty years, due to government support to conserve public buildings and lack of interest in heritage buildings owned by individuals, which has subjected them to deterioration, such as the buildings that have no historical value (Rashed \& Fikri \& Belqasi, 2013; Al-Manshawi, 2013), "i.e., the buildings that did not pass more than 100 years old and did not turn into an antiquity". Otherwise, there are some attempts of self-financing in Cairo for instance, where the project covers its expenses without the need for external interference, which will ensure the continuity of projects.

From the above-mentioned, it is evident the multiplicity of the bodies dealing with historical zones and the lack of a coordinating entity between theses bodies. This has led to the overlapping of roles and hindrance of the implementation of upgrading projects. In turn, this caused the emergence of many factors of shortcomings and deterioration in buildings and historical areas (Ministry of Culture, 2010; Al-Manshawi, 2013), which could be remedied in case of self-financing that is applied to a few conservation projects, although it is the best solution to ensure the continuity for implementation of conservation projects. 


\subsection{Self-financing for conserving architectural heritage of historical Tripoli}

The Municipality of Tripoli and a large number of the city lovers have undertaken to develop plans and alternatives to conserve and develop the historical sites. The main problem of Tripoli, which may be similar to the problems of developing societies in the restoration policies is finding funding sources (governmental or institutional), and raising the awareness of the community (including individuals and civil society organizations) regarding the importance of preserving their inherited architectural heritage (Nahas, 2001; El Taweel, 2006).

In reference to the previous examples of financing policies in the conservation project, the best financing method is to combine a large number of funding sources and not to rely on mono-financing. In addition to the state budget allocated to the conservation processes, recourse should be made to specialized international bodies and proposals must be offered for conservation projects that need to be financed. Furthermore, the civil society and nongovernmental organizations are also instrumental in ensuring continuity of conservation processes because of the pivotal role played by such institutions in raising the awareness and activating the popular participation of the society in conservation operations (by expressing opinions, working in projects of conservation or financial participation) ensures that projects will not deteriorate after the restoration is completed. Also, the presence of investment for the development of heritage areas and to generate profit on conservation projects to be used in the periodic maintenance of historical buildings, as the lack of maintenance makes restored areas deteriorate quickly. Most successful experiences in conservation projects either cut part of the grants provided and put them as a bank deposit to generate annual profit in order to complete maintenance processes and post-implementation follow-up or develop an investment project in the area, such as the Al-Azhar Park in Egypt. The result of this investment was directed to the maintenance and follow-up of these heritage areas, which is known as the self-financing (El Taweel, 2006; Ginzarly \& Teller, 2016).

It is worth noting in the conservation world that the reused buildings in vital applications are the most conserved of those that were restored and then left without use because their users are considered to be among the main bodies that seek to preserve the heritage and value buildings. As long as the heritage value of the building permits reuse and rehabilitation, it is preferable to establish a policy for each building with the appropriate use type in terms of the functional aspect (Nahas, 2001; Ginzarly \& Teller, 2016).

\section{Conclusion}

Conservation projects are indeed very complex as they usually involve a variety of legal, administrative, and financial aspects. Finance is without a doubt a governing aspect, yet there are mutual implications for both legal and administrative aspects. On the other hand, popular participation has proved to be a vital tool in decision making. Having scanned a variety of experiences in Britain, KSA and Egypt, the conservation in Tripoli can be handled as follows:

- Legal and administrative: unilateral system in work is the most difficult way in the conservation processes because there is no fair distribution of attention to all heritage and historical buildings in conservation projects, leading to the neglect of some buildings and deterioration.

One of the biggest problems facing the implementation of conservation projects is the multiplicity of entities that contribute administratively to the process of conservation and overlapping of responsibilities between them. Therefore, an organizing entity must always be present to help in setting the responsibilities of each of the contributors in conservation projects.

- Popular/community participation: many governments ignore the role of popular participation, whether financial, artistic or any other form. This leads to a deficiency in the knowledge of the value of buildings and maintaining them by users or occupants.

The role of media is the key role in motivating the process of participation, whether by announcing these projects or broadcasting the value of this distinctive architecture to school students and other different methods. 
The role of national associations and non-governmental organizations (NGOs) is in contributing, supporting and motivating popular participation, and investing the human capacities in historical areas.

- Financial aspects: among the consequences of mono-funding is the inability to restore all the historical and heritage buildings, leading to the deterioration of many buildings for the lack of financial support for the restoration.

The multiplicity of funding agencies in addition to the government support helps in the success of conservation projects, while alleviating the burden on the government economy and ensures continuity of the project.

The financial return resulting from tourists' visits to historical buildings and heritage areas, which helps in the development of the restored areas, as well as the revitalization of the area.

Self-financing has proved to provide sustainable and reliable return that is directly contributing to the continuity of conservation projects, i.e., the disbursement of the buildings' financial returns for the periodic maintenance cost of the same or other buildings to prevent deterioration. It is considered a key element for the success of conservation projects.

Furthermore, the following guidelines can contribute to the process of managing the conservation of architectural heritage and its problems in the city of Tripoli:

1. Directing all local entities/bodies to renew heritage areas of historical and value buildings, or the desired distinctive nature to be preserved.

2. Directing all parties to participate in the conservation project to ensure continuity.

3. Guiding all funding agencies and governments to rehabilitate heritage buildings in functions serving the community. This can result in the sympathy of community members with historical buildings.

4. Activating the role of the international organizations concerned, led by UNESCO (International Organization for Science, Arts, and Culture) as a major source of funding conservation projects in the form of aid.

5. Activating the role of private investments in financing conservation projects for the conservation of heritage buildings within the project of their adaptive reuse with profitable returns.

6. Activating the role of self-financing in conservation projects to ensure continuity in preserving the architectural heritage of historical Tripoli.

\section{Acknowledgement}

My profuse thank and gratefulness goes to all my colleagues at Beirut Arab University, specially Prof. Mohamed Assem Hanafi, Dr. Mary Felix and Mrs. Samar Hamieh for their support and perceptive advices.

\section{Reference}

Abdel Fattah, S. E. M. (2012). Funding Management of Historical Areas Rehabilitation Projects, Cairo Case Study. Msc thesis, Faculty of Engineering, Helwan University, Egypt. Retrieved from http://www.cpas-egypt.com/pdf/ShehabMohamed/Ms.c/002.pdf

Aga Khan Historic Cities Programme (AKHCP). (2007). the Azhar Park Project in Cairo and the Conservation and Revitalization of Darb AlAhmar. the Aga Khan Trust for Culture, Switzerland. Retrieved https://ahmadladhani.files.wordpress.com/2009/06/historic_cities_ah3.pdf

Al-Manshawi, A. (2013). Partnership in Urban Conservation Projects under the Globalization of the $\left(20^{\text {th }}-21^{\text {st }}\right)$ Century in Egypt. PhD thesis, Faculty of Engineering, Cairo University, Egypt.

Bunge-Vivier, V. \& Martínez-Ballesté, A. (2017). Factors that influence the success of conservation programs in common property resources in Mexico. Uopen Journals (ISSN 1875-0281), International Journal of the Commons, 11(1), 487-507. doi:https://doi.org/10.18352/ijc.718

Business Dictionary. (2019). WebFinance Inc. Retrieved from http://www.businessdictionary.com/definition/self-financing.html

Clausse, G. (2013). Funding Sources for Preserving Cultural Heritage Monuments and Sites. The Specific Case of the "7 Most Endangered", Initiative by EIB-I and Europa Nostra. Retrieved from https://www.globalheritagefund.org/ 
El Borombaly, H. (2015). Building Regulation Control for the Conservation of Architecture and Urban Heritage to the Value Areas. Conference: Al Qassim Architecture 2 $2^{\text {nd }}$ Forum; Urban Heritage principles and values, Al Qassim University on April 2015. doi: https://doi.org/10.13140/RG.2.1.4907.9206.

El Esawy, M. A. A. (2012). A Comparative Study of Urban Heritage Conservation Policies. $3^{\text {rd }}$ International Urban Conservation Conference and Exhibition, Dubai, United Arab Emirates. Retrieved from https://www.fayoum.edu.eg/.../Architectural/DrMohammadE.aspx

El Taweel, H. A. M. (2006). Rehabilitation for Traditional Centers of Arab Cities: The Lebanese Experiment - Case Study. Arab Cities Magazine, Arab Towns Organization, 138(2), 137-154. Retrieved from http://www.lonaard.com/ar/arc-8.pdf

Etzioni, A. (2007). Reconstruction: An Agenda. Journal of Intervention and Statebuilding, Taylor \& Francis Group (Routledge), New York, USA, 1(1), 27-45. doi:https://doi.org/10.1080/17502970601075881

Felix, M. (2007). Value Engineering as a Key Enrolment in Architecture and Urban Conservation Process. Msc thesis, Faculty of engineeing, Cairo University, Egypt.

Ginzarly, M., \& Teller, J. (2016). Heritage Conservation in River Corridor Cities: The Case of Tripoli, Lebanon. Conference: The 23 ${ }^{\text {rd }}$ International Seminar on Urban Form (ISUF 2016), Nanjing, China. Retrieved https://www.researchgate.net/publication/309297231_Heritage_Conservation_in_River_Corridor_Cities_The_Case_of_Tripoli_Lebanon

Hanafi, M. A. (1993). Development and Conservation with Special Reference to the Turkish Town of Alexandria. PhD thesis, Institute of Advanced Architectural Studies, University of York, U.K.

Harrison, L. E. (2006). Culture and Economic Development, How Much Does Culture Matter. Cato Unbound, Journal of Debate, Lead Essay. Retrieved from https://www.cato-unbound.org/2006/12/03/lawrence-e-harrison/culture-economic-development

Hezel, S. J. \& Francis, X. (2009). The Role of Culture in Economic Development. Micsemesian Counselor, 8(77), 1-20. Retrieved from http://www.micsem.org/pubs/counselor/pdf/mc77.pdf

Khan, M.M., Zhang, J., Hashmi, M.S., Bashir, M. (2010). Cultural Values and Economic Growth in Asia: An Empirical Analysis. International $\begin{array}{llllll}\text { Journal of } & \text { Business } & \text { Social } & \text { Science, } & 1(2), & 15-27 .\end{array}$ https://pdfs.semanticscholar.org/b3a7/be08e32922356f08a61473c5b30f314b9fce.pdf

Ministry of Culture. (2010). Guiding Manual: Principles and Criteria for Civilizational Coordination of Buildings and Heritage Areas of Distinctive Value. Approved by the Supreme Council for Planning and Urban Development, in accordance with Law No. 119 of 2008 and its Executive Regulations. National Organization for Urban Harmony, Egypt, 1(1), 1-48. Retrieved from http://www.cpasegypt.com/pdf/National_Organization_for_Urban_Harmony/01/001/01.pdf

Nahas, C. (2001). Stakeholder Analysis and Social Assessment for the Proposed Cultural Heritage and Tourism Development Project. Council for Development and Reconstruction (CDR), Beirut, Lebanon. Retrieved from https://charbelnahas.org/?p=696

Pålsson Skarin, I. (2011). A Finance Model for the Built Cultural Heritage - Proposals for improvements of future Heritage Economics. Lund University, Sweden. ISBN 978-91-7740-103-2. Retrieved from http://portal.research.lu.se/portal/files/6416876/2203938.pdf

Pickard, R. (2009). Funding the Architectural Heritage: a Guide to Policies and Examples. Council of Europe Publishing, France. ISBN 978-92871-6498-8. Retrieved from https://courseworks2.columbia.edu/files/588373/download?download_frd=1

Pollard, S. R. \& Cousins, T. (2008). Governing wetlands in the commons: the challenges to management of complex systems. The IASC Biennial Conference; Governing shared Resources: connecting local experience to global challenges, Cheltenham, England, 1(1), 2-24. Retrieved from http://award.wordpress.hupu-labs.biz/wp-content/uploads/sites/2/2015/11/Governing-wetlands-in-the-commons_Cousins_Pollard_2008.pdf

Rashed, A. \& Fikri, M. M. \& Belqasi, M. (2013). Investment as a Cornerstone for Conservation Operations in Heritage Areas: Case Study of AlMoez Ledin Allah Al Fatimi Street. $3^{\text {rd }}$ National Urban Heritage Forum, Al-Madinah Al-Monawara, Saudi Arabia.

Sultan, M. S. (2013). Urban Heritage Finance Issues: Strategic Framework for the Promotion of Conservation and Protection of Heritage. $3^{\text {rd }}$ National Urban Heritage Forum, Al-Madinah Al-Monawara, Saudi Arabia. Retrieved from https://scholar.cu.edu.eg/?q=mmyoussif/files/qdy_tmwyl_ltrth_lmrny.docx.

Tabellini, G. (2010). Culture and Institutions: Economic Development in the Regions of Europe. Journal of the European Economic Association, 8(4), 677-716. doi:https://doi.org/10.1111/j.1542-4774.2010.tb00537.x

UNESCO World Heritage Center (WHC), World Heritage Sites Management in Egypt. (2012). Urban Regeneration Project for Historic Cairo (URHC). United Nations Educational, Scientific and Cultural Organization, Business Report for the Period July 2010 to June 2012 . Retrieved from http://whc.unesco.org/document/120190

Yousif, M. M. A.. (2014). Investment Programs in Architectural Heritage and Means of Funding based on the Arab and International Experiences. Journal of Urban Research, Faculty of Urban and Regional Planning, Cairo University, Egypt, 12(ISSN 2090-0694), 13-27. Retrieved from https://www.tinyurl.com/za96knv 